MATEC Web of Conferences 22,04013 (2015)

DOI: $10.1051 /$ matec conf/ 20152204013

(C) Owned by the authors, published by EDP Sciences, 2015

\title{
A Case Study on the Selection of Purification Project of Lake
}

\author{
Shilong Shen \& Wei Liu \\ College of Water Resources and Environment, China Three Gorges University, Yichang, China \\ Zhangcheng Yuan \\ Nari Technology Development Limited Company, Nanjing, China
}

\begin{abstract}
This paper will mainly talk about best scheme for the water purification project of the Lake. The engineering used the water diversion metabolism method to purify the water. If the lake area and the water volume are small, the metabolic cycle is relatively short; if the lake area and the water volume are large, the metabolic cycle is relatively long. Simultaneously, the larger the water flow is, the shorter the metabolic cycle period is and the higher the average metabolic rate is. The process of the water metabolism is in agreement with the direction of the water flow movement. With the gradual metabolism of water, different water bodies begin to dilute and diffuse. The engineers will choose the most appropriate water division project according to different water division volumes and water division routes.
\end{abstract}

Keywords: water metabolism; water quality; water environmental remediation project; Water metabolism cycle

\section{INTRODUCTION}

\subsection{The Cihu Lakewater purification pro- ject alternatives}

The lake provides abundant water resources for mankind, and provides a wealth of tourism, vacation and leisure resources of spirit, but also receives more and more all kinds of pollution, such as, people dumping garbage, waste water, sewage and other pollution. Due to the lack of protection methods of the ecological environment, more and more industrial and biological sewage pollutants have caused the extinction of biological resources and deterioration of water quality, which has brought serious disaster to human beings. More and more people are concerned about the problems of the protection of the ecological environment. In order to be able to grow in a healthy atmosphere, it is necessary for us to put forward a new scheme for controlling pollution. If we know the water's stable velocity of the lake and the approximate number of pollutants, we can take emergency measures to control pollutants. The lake water governance is a difficult task, because in general the lake covers a relatively large area, and the pollution source is more complicated. It is difficult to specify all the pollution causes. Usually in control of water pollution by the water itself to self-purification capacity to alleviate pollution, this pollution of the river is generally effective, but for the polluted lake waters it's not feasible. So how do we do to control water pollution? The usual methods are the rain sewage interception, point sources, and water diversion metabolism. Cihu Lake in Hubei Province used water diversion metabolic water improvement method, the water body metabolism and the most economic water diversion path.

\section{ESTABLISHMENT OF MATHEMATICAL MODEL}

Cihu Lake is located in the southeast of Hubei Province, together with Qinggang Lake in the same basin, among which Cihu Lake is the biggest one, which is about $9.17 \mathrm{~km}^{2}$. Qingshan Lake locates in North of Qinggang Lake, whose water area is $0.52 \mathrm{~km}^{2}$, and Qinggang Lake's water area is $0.70 \mathrm{~km}^{2}$. These lakes are linked with tunnel, culvert and ecological port channel. As water diversion area, Qingshan Lake and Qinggang Lake are both added into the scope of numerical simulation; according to the lake size and connection status, in order to simulate the water metabolism at initial time, we assume that the lake contains one unit, then the introduction of water tracer concentration is 0 , and after a period of water diversion, the tracer concentration in the lake is 0.7 . As a result, the water metabolism rate is $30 \%$.

The formula for computing the metabolism rate is shown as follows:

$\delta_{i}=\left(1-\gamma_{i}\right) \times 100 \%$

Where, $\delta_{i}$ is metabolic rate of the $\mathrm{i}$ in Lake area; $\gamma_{i}$ is the tracer concentration in the i Lake area; Cihu Lake shoreline twists and turns, contains more than one lake, and the shape is irregular, the surface area of the status quo is $9.16 \mathrm{~km}^{2}$, and the average water depth is only $1.75 \mathrm{~m}$. According to the characteristics of Cihu Lake above, this study uses a 2D hydrodynamic mass orthogonal body fitted curvilinear coordinates transport mathematical model. The characteristics, the mathematical model results of complete information, conducive to adjusting scheme comparison, save the research cycle. It is convenient for long-term storage, and the economical efficiency and accuracy 
MATEC Web of Conferences

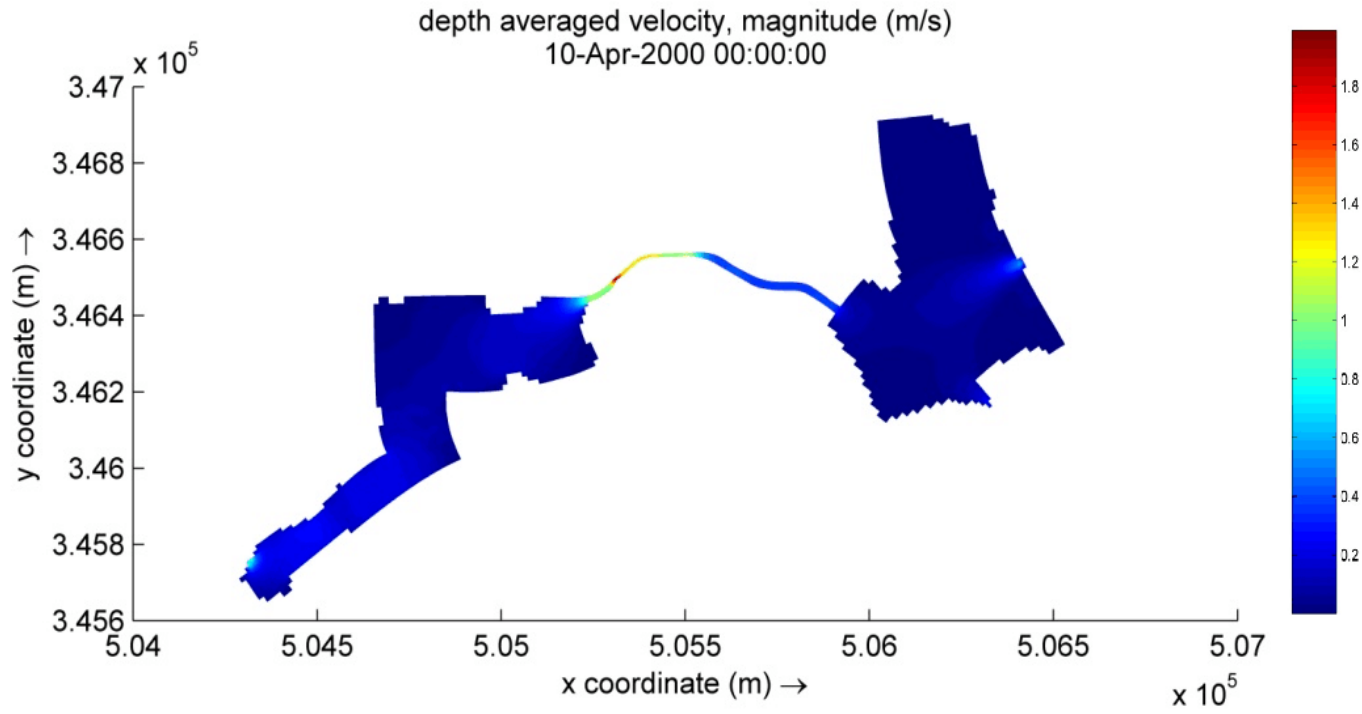

Figure 1. Qingshan Lake velocity distribution (scheme one)scheme one

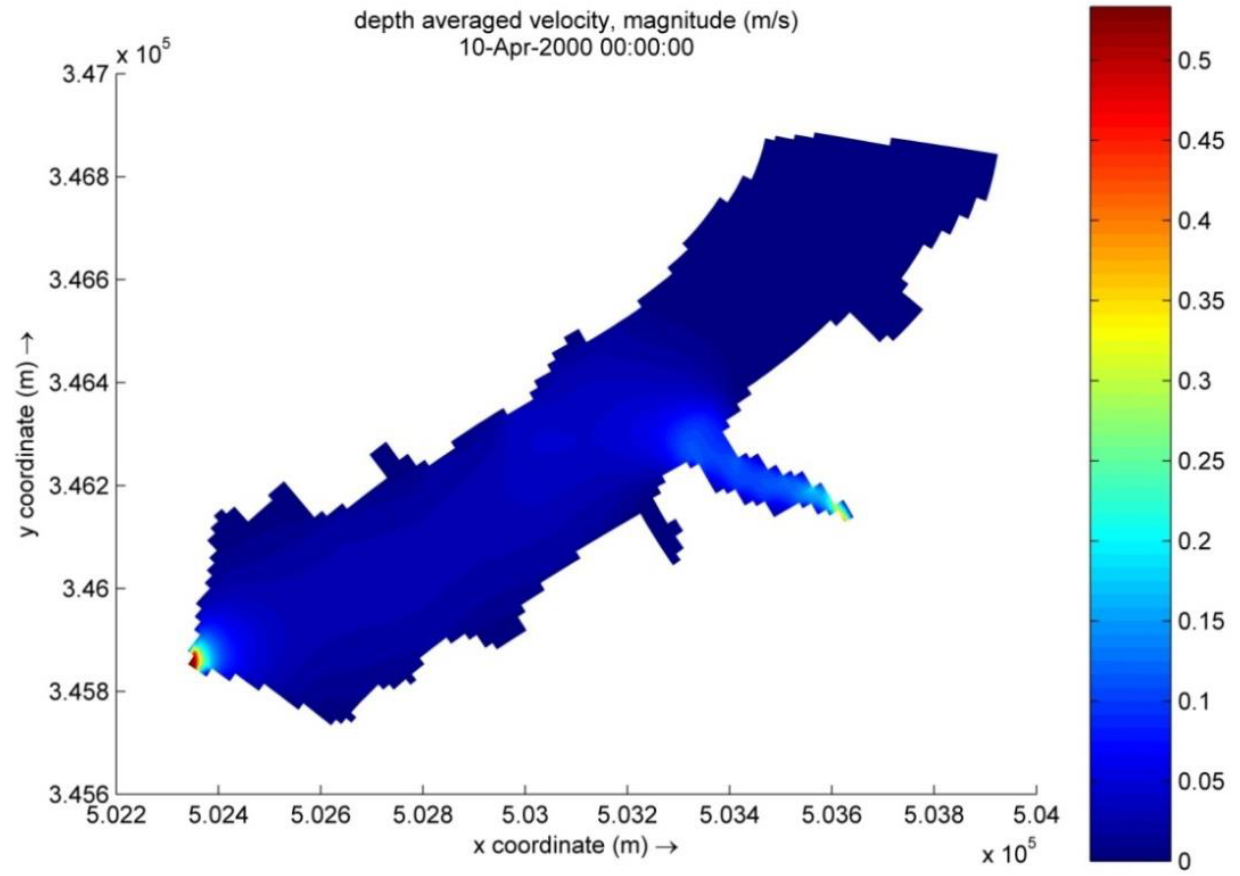

Figure 2. Hong Lake velocity distribution (scheme one)scheme one can meet the needs of engineering, which has been widely used in mature technology, suitable for the study. The water power part control equation model includes continuity equation and momentum equation of horizontal direction. The equation of continuity is shown below:

$$
\frac{\partial \zeta}{\partial t}+\frac{1}{C_{\xi} C_{\eta}} \frac{\partial}{\partial \xi}\left(C_{\eta} H u\right)+\frac{1}{C_{\xi} C_{\eta}} \frac{\partial}{\partial \eta}\left(C_{\xi} H v\right)=0
$$

Where, $\xi$ is the equation of continuity; $\eta$ is the two orthogonal curvilinear coordinates in orthogonal curvilinear coordinate; $\zeta$ is the water level; and $h$ is the depth of the water; and $H$ is the whole water depth. 
ICETA 2015

\section{SCHEME ONE WATER DIVERSION ROUTE}

\subsection{Scheme one: Qingshan Lake water metabolism in the basic situation.}

First of all, in Scheme one, divert $21 \mathrm{~m}^{3} / \mathrm{s}$ of water from Yangtze River to Qingshan Lake. Simultaneously, respectively divert $8 \mathrm{~m}^{3} / \mathrm{s}$ and $13 \mathrm{~m} 3 / \mathrm{s}$ (total 21 $\mathrm{m}^{3} / \mathrm{s}$ ) from Qingshan Lake to the North Cihu Lake and Qinggang Lake.

The order of water metabolism is consistent to flow direction, promoting from the inflow to outflow, diffusing and mixing with original water simultaneously, which lead to the dilution of the tracer concentration. Owing to the small volume of Qingshang Lake, the water metabolic is faster, more comprehensive without obvious stagnant pool in this large flow scheme, and can be completed after $24 \mathrm{~h}$.

\subsection{Basic situation of scheme one Qinggang Lake metabolism.}

In scheme one, the income flow from Qingshan Lake for Qinggang Lake is $13 \mathrm{~m}^{3} / \mathrm{s}$, and it's the same outflow rate to Cihu Lake, metabolizing itself at the same time. Qingshan Lake originates from the central of Qinggang east coast, flowing out to the southwest and afflux into the Cihu Lake. Located at the southwest water area, Qinggang lake forms a large recirculation zone in the Northeast lake area, whose mainstream is controlled by the location of I/O flow. The process of metabolism is well-distributed without obvious stagnant pool. Although backflow under a low rate in large field still exists in the Northeast of the lake area, the speed of metabolism is basically coherent to the mainstream because the water area is shallow and the volume is small. At the beginning of diversion process, the water of Qinggang Lake is originated from QingShan lake. As a result, its metabolism period is longer than QingShan lake's, which is near 3 4 days.

\subsection{Basic situation of scheme one Cihu Lake water metabolism.}

In scheme one, the Cihu Lake is the final node water diversion line; it is also the main object of water environment improvement project. Cihu Lake has three water inlets. They are located in the magnetic North Lake East and West and South West lake. The magnetic North eastern part of the lake at the entrance is to flow directly through two bridge arches of the bridge to the outlet in Hangzhou East Road, and the process is relatively short, the North and south magnetic on the west side of the lake two inflow port to flow along the lake from west to east flow. Because the North and South of Cihu Lake hasn't a valid connection channel, and the two waters exchange rarely, only near the outlet of Hangzhou road bridge, through mixing a small amount of exchange. This Cihu Lake average metabolic rate was $36.6 \%$, whereas the North Lake average metabolic rate is $44.8 \%$, and South Lake av- erage metabolic rate is $25.8 \%$ The North lake flow is much larger than the South Lake, and the metabolic rate is also higher than the South lake. Cihu Lake average metabolic rate is shown in the table 1.

Table 1. Cihu Lake average metabolic rate (\%)

\begin{tabular}{llllc}
\hline Scheme & $\begin{array}{l}\text { Time } \\
\text { (day) }\end{array}$ & Cihu Lake & $\begin{array}{l}\text { South } \\
\text { Cihu } \\
\text { Lake }\end{array}$ & $\begin{array}{l}\text { North } \\
\text { Cihu } \\
\text { Lake }\end{array}$ \\
\cline { 3 - 5 } & & & 25.1 & 27.6 \\
Scheme & 3 & 26.6 & 38.5 & 60.4 \\
1 & 7 & 51.0 & 46.2 & 74.9 \\
& 10 & 62.6 & 65.9 & 93.6 \\
& 20 & 81.7 & 76.0 & 96.0 \\
& 45 & 85 & 86.0 & 98.0 \\
\hline
\end{tabular}

\section{SCHEME TWO WATER DIVERSION ROUTE}

\subsection{Scheme two Qingshan Lake water metabolism in} the basic situation.

Divert $8 \mathrm{~m}^{3} / \mathrm{s}$ of Yangtze River through the Laohutou barrier gate station to Qinggang Lake; respectively Divert $2 \mathrm{~m}^{3} / \mathrm{s}$ of Qinggang lake through Panlongshan Tunnel to Qingshan Lake , $4 \mathrm{~m}^{3} / \mathrm{s}$ through Wang Jia Qiao ecological port channel to the North Cihu Lake, $2 \mathrm{~m}^{3} / \mathrm{s}$ through the South Lake Ecological Port Channel to South Lake, finally, it diverts $8 \mathrm{~m}^{3} / \mathrm{s}$ of Cihu Lake through Yangsheng barrier gate station to the Yangtze river.

In scheme two, Qingshan Lake diverts $2 \mathrm{~m}^{3} / \mathrm{s}$ water to Qinggang Lake, and diverts equivalent water through Qingshan Lake into the Yangtze river. Qinggang lake water comes from the department, and the entrance velocity is about $0.3 \mathrm{~m} / \mathrm{s}$. Lake water metabolism is also well flow to the successive direction, and though velocity of recirculation, the region is very small, but as a result of the mainstream, zone flow velocity of the absolute numerical value is limited, so the child lake can obtain complete metabolism, without sluggish water existing. Because the flow is relatively small, and water diversion is the acceptance of early Qinggang Lake original water, under this scheme, Qingshan Lake water body metabolic cycle is longer than scheme one, after 15 days later, the lake water body has finished basic metabolism.

\subsection{Basic situation of scheme two Qinggang Lake metabolism.}

In scheme two, divert $8 \mathrm{~m} 3 / \mathrm{s}$ of Yangtze River water into the green port lake. Simultaneously, divert water from Qinggang Lake North Lake and respectively magnetic Qingshan Lake water directly to $6 \mathrm{~m}^{3} / \mathrm{s}, 2$ $\mathrm{m}^{3} / \mathrm{s}$ (totally $8 \mathrm{~m}^{3} / \mathrm{s}$ ). By pumping station, the flow into the lake from the Northeast of the entrance velocity is larger, up to $0.3 \mathrm{~m} / \mathrm{s}$, which is respectively located in the east coast of Lake in central and southwest, and the whole lake water flow is smooth with full 


\section{MATEC Web of Conferences}

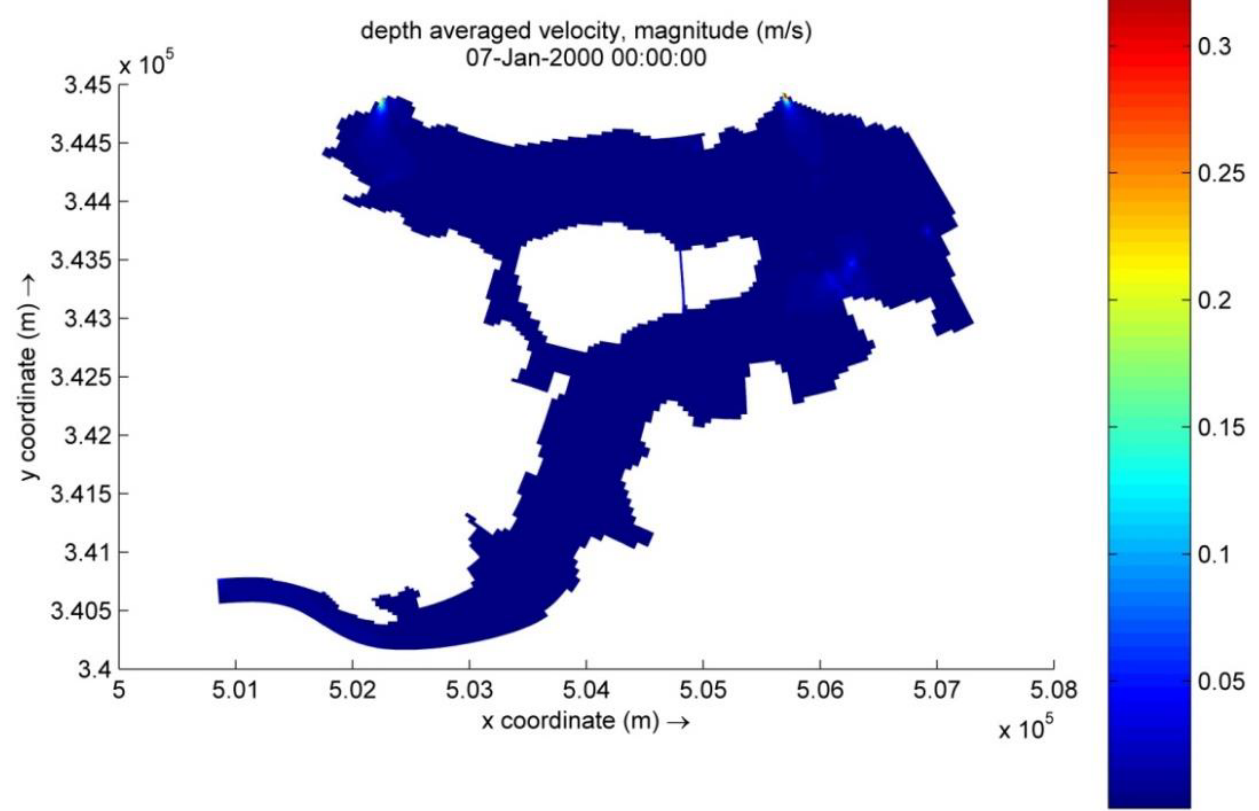

Figure 3. Magnetic Lake velocity distribution (scheme one)scheme one

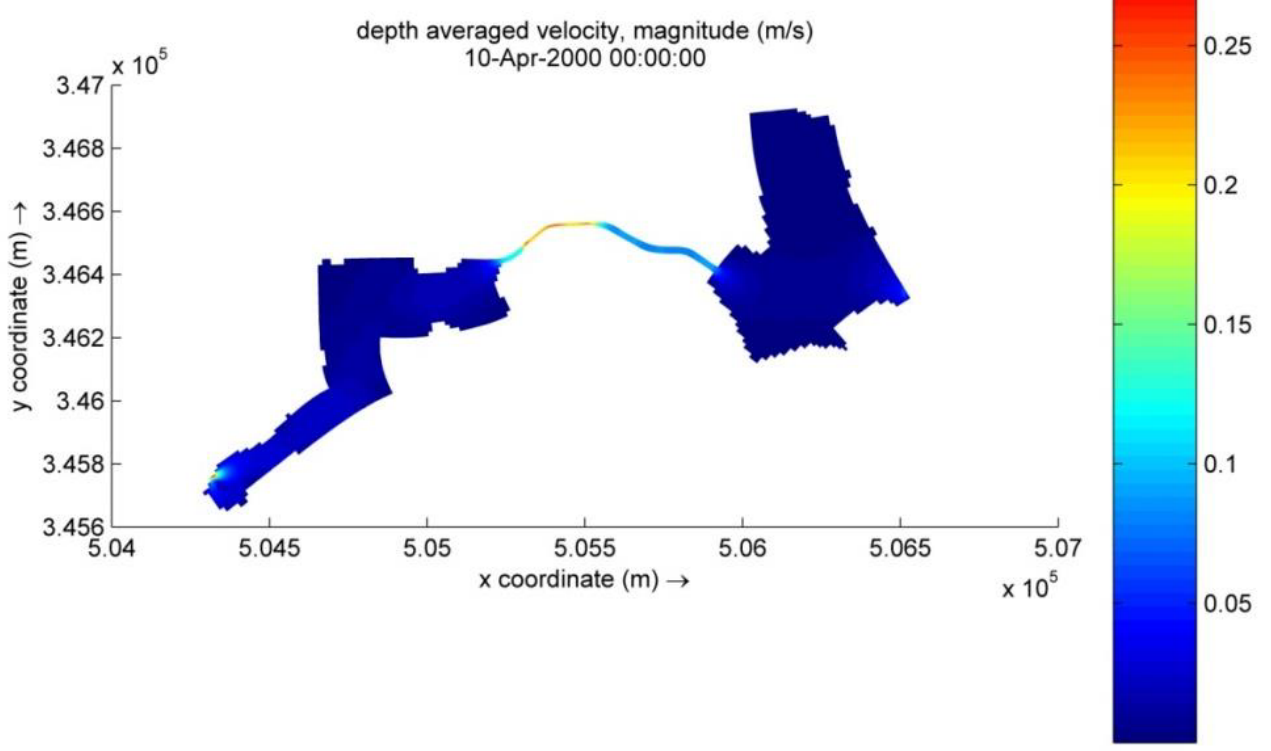

Figure 4. Qingshan Lake velocity distribution (scheme one)scheme two

section flow. The lake is also the water flow direction metabolism cycles of Hong Lake in this scheme are from Northeast to Southwest metabolism gradually. longer than that of scheme one. After 9 days, the lake Because current flow is relatively small, the water has completed basic metabolism. 


\section{ICETA 2015}

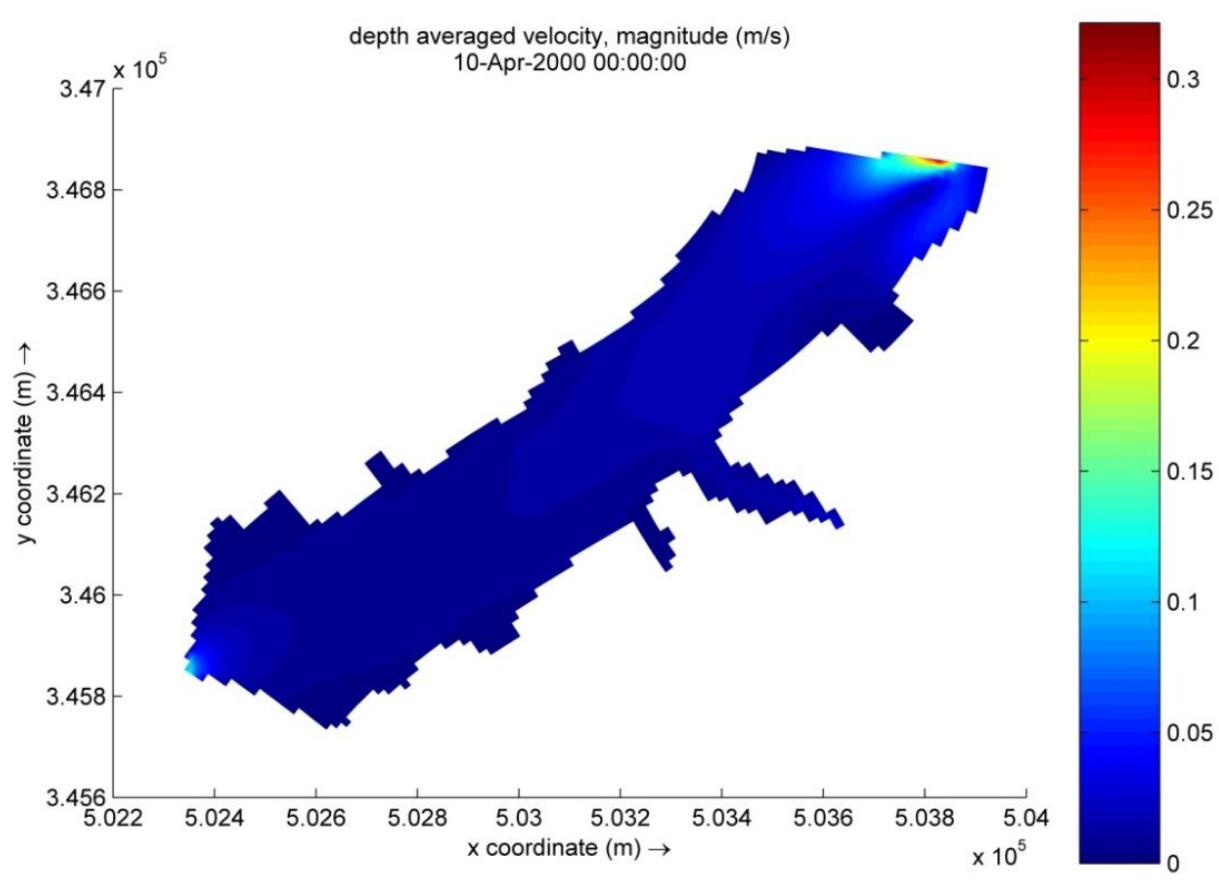

Figure 5. Hong Lake velocity distribution (scheme two)scheme two

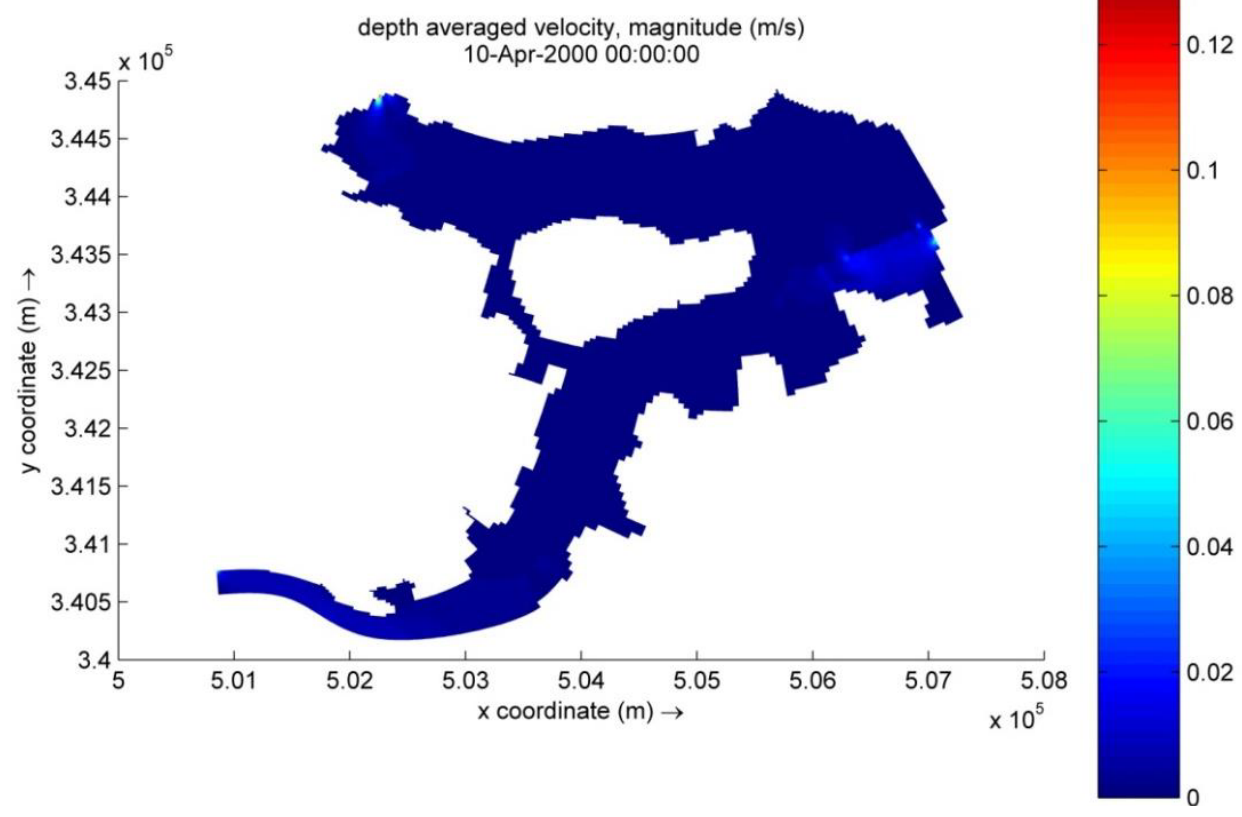

Figure 6. Magnetic Lake velocity distribution (scheme two)scheme two

4.3 Basic situation of scheme two Cihu Lake water so the water metabolism cycle is relatively long. Unmetabolism.

In the scheme two of the conditions, Cihu Lake water volume is larger, and stream flow is relatively small, der the scheme of Cihu Lake, only two westerns in a mouth (North and south each) to flow are respectively $4 \mathrm{~m}^{3} / \mathrm{s}$ and $2 \mathrm{~m}^{3} / \mathrm{s}$, and the total flow into the lake is far less than the scheme one They were derived from 


\section{MATEC Web of Conferences}

Qinggang Lake. The magnetic North and South on the west side of the lake two inflow port to flow along the lake from west to east flow, flow more smoothly, and only local convex and concave bank is in effective range of reflux. The velocity is very small. The magnetic North West Lake entrance velocity is large, about $0.1 \mathrm{~m} / \mathrm{s}$, and about $0.05 \mathrm{~m} / \mathrm{s}$ for South Lake entrance velocity. For North and South Cihu Lake is without a valid connection channel, the two waters exchange rarely, which is only near the outlet, and through Hangzhou road bridge which has a small amount of exchange mixing. This scheme is running for 90 days, and the levels of Cihu Lake were body metabolic rate which can reach $80 \%$, and the metabolic process also is to the east along the direction of water movement successively. Although the magnetic North Lake into the flow is South Lake, but because the volume is smaller, in the metabolic process of the average metabolic rate is higher than that of the magnetic North Lake, and the two gaps decrease with the increase of time. The period of 45 days has been more or less the same to Cihu Lake average metabolic rate which is shown in the following table:

\begin{tabular}{|c|c|c|c|c|}
\hline \multirow[t]{4}{*}{ Scheme } & \multirow{4}{*}{$\begin{array}{l}\text { Time } \\
\text { (day) }\end{array}$} & \multicolumn{3}{|c|}{ The Lake District } \\
\hline & & Cihu Lake & South & North \\
\hline & & & Cihu & Cihu \\
\hline & & & Lake & Lake \\
\hline \multirow[t]{2}{*}{ Scheme } & 3 & 3.2 & 4.5 & 2.3 \\
\hline & 7 & 10.3 & 12.8 & 8.4 \\
\hline \multirow[t]{4}{*}{2} & 10 & 15.1 & 17.7 & 13.0 \\
\hline & 20 & 28.8 & 31.1 & 27.1 \\
\hline & 45 & 54.1 & 55.4 & 53.1 \\
\hline & 90 & 79.1 & 79.6 & 78.7 \\
\hline
\end{tabular}

5 SCHEME THREE WATER DIVERSION ROUTE

5.1 Scheme three Qingshan Lake water metabolism in the basic situation.

First of all, in Scheme three, Divert $8 \mathrm{~m}^{3} / \mathrm{s}$ of Yangtze River into Qingshan Lake. Simultaneously, respectively divert $2 \mathrm{~m}^{3} / \mathrm{s}$ and $6 \mathrm{~m}^{3} / \mathrm{s}$ (total $8 \mathrm{~m}^{3} / \mathrm{s}$ ) from Qingshan Lake to the North of Cihu Lake and Qinggang Lake directly. Qinggang Lake flows respectively into the North and South of Cihu Lake. Qingshan Lake flows into the lake side, and the maximum velocity of the water flow is about $0.2 \mathrm{~m} / \mathrm{s}$. It is subject to exporting position effect and partial to South Lake District, and the recirculation zone velocity of the formation of a large range of back flow region in $\mathrm{Hu}-$ bei Department of lakes is very small. The mainstream area flow in general is not more than $0.04 \mathrm{~m} / \mathrm{s}$. In the lake metabolism along the successive direction of water movement, each sub lake can be in complete metabolism, and no stagnant water areas exist. After 15 days, the lake has completed basic metabolism.
5.2 Basic situation of scheme three Qinggang Lake metabolism.

The scheme three Qinggang lake to flow and metabolism and scheme one and 2 are different, the flow in the same position and scheme one and scheme two, it accesses to the same flow. Qingshan Lake flows $6 \mathrm{~m}^{3} / \mathrm{s}$, entering from the east coast of lake central entrance Qinggang, outflowing from the southwest exit, to the direction of Cihu Lake. The maximum velocity appears in the lake near the exit, which is about $0.1 \mathrm{~m} / \mathrm{s}$, and the inlet velocity is about $0.1 \mathrm{~m} / \mathrm{s}$. The velocity in the mainstream area is about $0.04 \mathrm{~m} / \mathrm{s}$, and the recirculation zone velocity is very small, less than $0.02 \mathrm{~m} / \mathrm{s}$. Lake metabolism process is relatively uniform, with no obvious backwater region, because the flow is far less than the 1 scheme, making its metabolism period prolonged, taking 15 days of completion of basic metabolism.

\subsection{The basic situation of scheme three Cihu Lake water metabolism.}

The scheme three of Cihu Lake flow conditions and the initial state and the scheme two is consistent, such programs run 90 days later, Cihu Lake levels were body metabolic rate can reach $80 \%$, the metabolic process also is to the east along the direction of water movement from successive. In different periods of watering the average metabolic rate gives the scheme three of the conditions and The change rule and also the scheme two is consistent, numerical value is more close to the. Cihu Lake average metabolic rate for shown in the table 3.

Table 3. Cihu Lake average metabolic rate (\%)

\begin{tabular}{cllll} 
Scheme & $\begin{array}{l}\text { Time } \\
\text { (day) }\end{array}$ & \multicolumn{3}{c}{ The Lake District } \\
\cline { 3 - 5 } & & Cihu Lake & $\begin{array}{l}\text { South } \\
\text { Cihu } \\
\text { Lake }\end{array}$ & $\begin{array}{l}\text { North } \\
\text { Cihu } \\
\text { Lake }\end{array}$ \\
\hline Scheme & 3 & 3.1 & 6.1 & 0.8 \\
& 7 & 10.5 & 19.3 & 3.7 \\
3 & 10 & 19.5 & 25.9 & 16.8 \\
& 20 & 27.4 & 36.1 & 23.8 \\
& 45 & 52.3 & 55.7 & 40.3 \\
& 90 & 79.2 & 63.1 & 74.7 \\
\hline
\end{tabular}

\section{PRELIMINARY ANALYSIS OF WATER QUALITY CHANGE OF LAKE}

Effect of water diversion project on the water quality change is also affected by the lake water quality and the water quality of the original effect, which cannot be completed to the average metabolic rate evaluation of water. Therefore, based on the previous calculation of metabolic rate, only considering the dilution of self-purification capacity conditions, according to the main index of water quality of Yangtze River and magnetic Lake (COD, TN, TN) on the indexes of water quality monitoring data, the author has carried out the preliminary analysis and calculation of concentration change on Cihu Lake. Among them, the Yangtze 
ICETA 2015

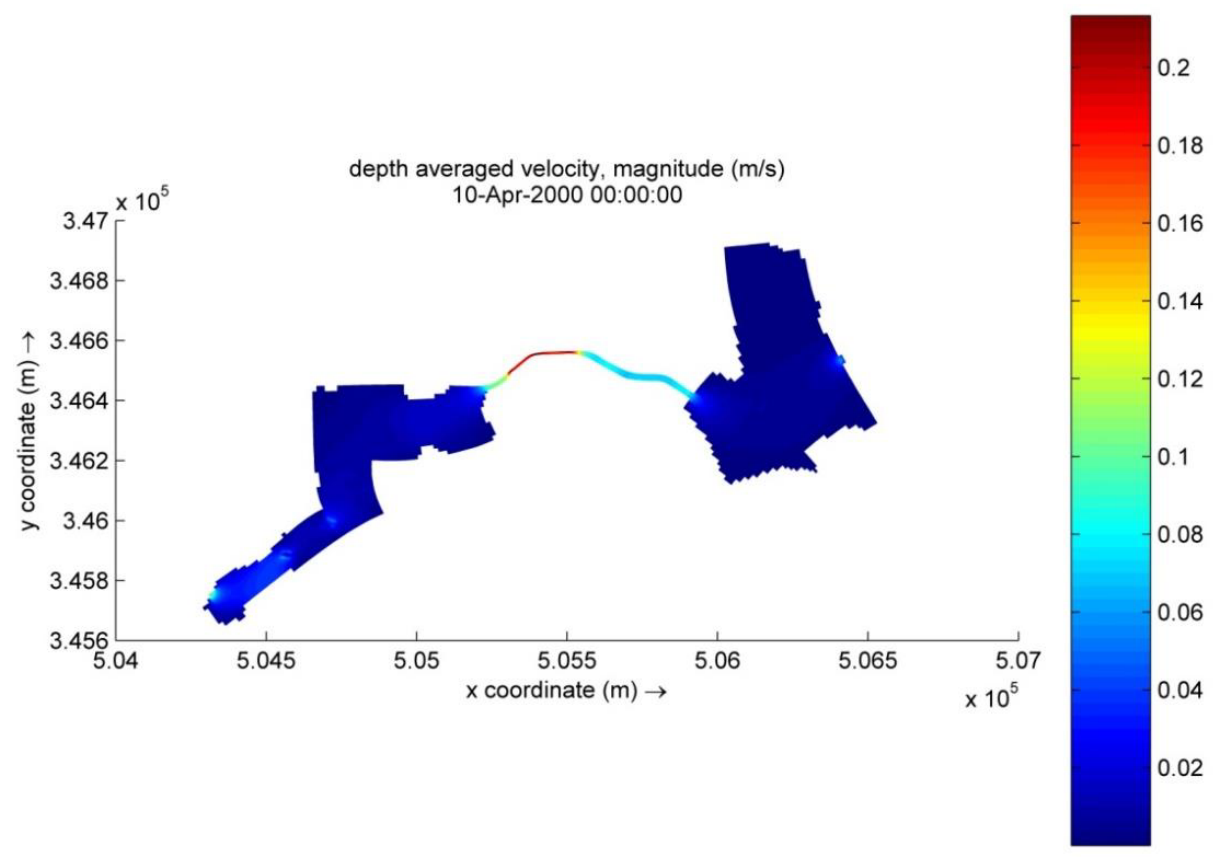

Figure 7. Qingshan Lake velocity distribution (scheme three)scheme three

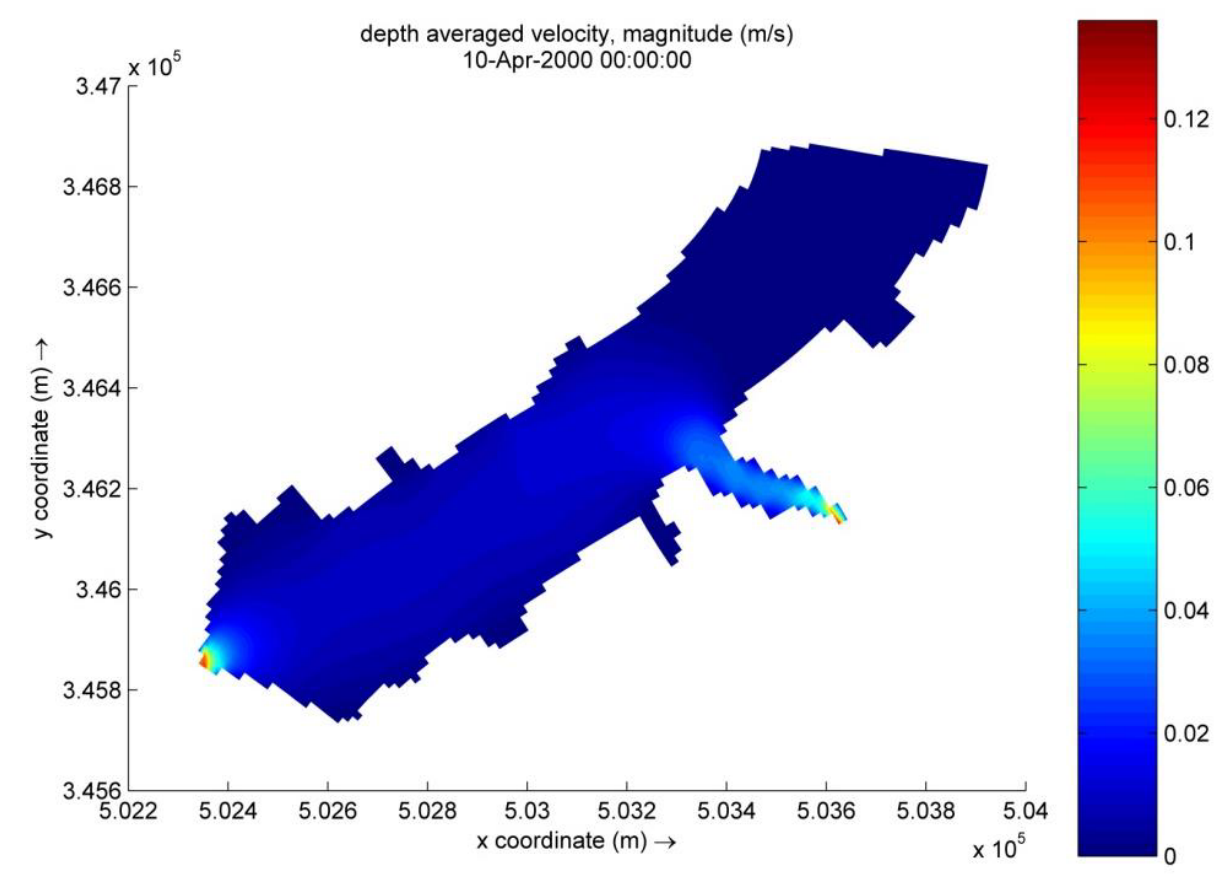

Figure 8 . Hong Lake velocity distribution (scheme three)

River COD is 5.37, the Cihu Lake is 24.38; the Yangtze River TN is 0.1946 , the Cihu Lake is 2.19 ; the Yangtze River TP is 0.0917, the Cihu Lake 0.1267.
From the data in the table we can see, in the numerical simulation conditions, using schemes two and three to run 90 days, COD concentration was below 


\section{MATEC Web of Conferences}

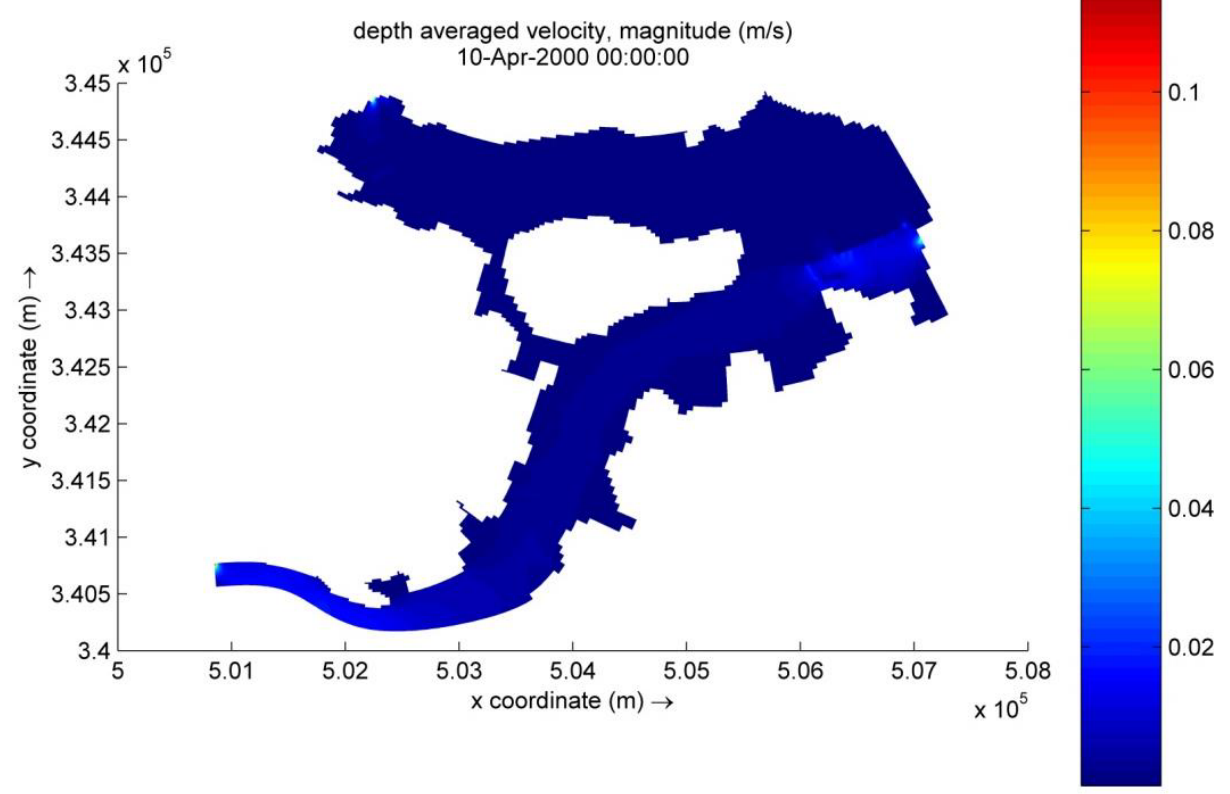

Figure 9. Cihu Lake velocity distribution (scheme three)

ten, and the water quality categories increased from the original five class to better than IV; TN dropped to about 0.5 , and the water quality category by the inferior class increased close to the class II; TP to 0.1 and the following categories of water quality improved.

\section{CONCLUSIONS}

Different schemes have different metabolic cycles and different average metabolic rates. The bigger the diversion yield is, the shorter the metabolic cycle will be. This will lead to greater average metabolic rate. Water metabolism path is consistent with water flow path. So water metabolism successively occurs along with water movement, dilution and diffusion. The metabolic cycle of Qinshan Lake and Qinggang Lake is comparatively short for the area and volume of them are relatively small. In scheme one, the metabolic cycle periods of them are respectively one day and 3-4 days; In scheme two, the metabolic cycle periods of them are respectively 15 day and 9 days; In project scheme, the metabolic cycle periods of them are both around 15 days. The bigger the area and volume of water are, the longer the metabolic cycle will be. In scheme one, the average metabolic rate in 20 days can reach around $80 \%$. In scheme two and scheme three, the average metabolic rate in 90 days can reach around $80 \%$. Under the same total water flow, the diversion path in scheme three will have the greatest economical effect along with the lowest influence on the whole envi- ronment. So the water division scheme three is the most appropriate one.

\section{REFERENCES}

[1] Hongbo Zhang, Xin Chen, Yimin Wang. \& Qiang Huang. 2010. The Baoji gorge water diversion effect on Weihe hydrological regularity and ecological system. Journal of Northwest Agriculture and Forestry University (Natural Science Edition), 04: 226-234.

[2] Qicai Lin. \& Huaien Li. 2010. Effects of Baoji gorge water diversion of Weihe ecological base flow and Study on its security. Journal of Arid Land Resources and Environment, 11:114-119.

[3] Xiong Cheng, Xinyu Wu, Springfield Cheng. \& Xiha Guo. 2012. The Songjiang inter basin diversion cascade hydropower stations group long-term optimal scheduling method. Journal of Hydraulic Engineering, 04:493-501.

[4] Wenting Hu. 2012. Microbial Ecology Investigation and study of. Shanghai Ocean University Lake and its diversion channel sediments.

[5] Xiaoyu Wang. 2008. of Northeast Normal University and ecological effects of sediment dredging and water diversion project of lake of shallow urban.

[6] Wang Rain. 2008. By Dredging and Water Diversion Engineering for Small Shallow Water of the Lake Urban Ecological Effect. The Northeast Normal University. 